\title{
Prevalence of Four Common Bee RNA Viruses in Eastern Bee Populations in Yunnan Province, China
}

\author{
Miao Wang ${ }^{1}$, Junlong $\mathrm{Bi}^{2,3}$, Lei Wang ${ }^{1,3}$, Danyin Zhou ${ }^{1}$, Xiaotian Ma ${ }^{1}$, Wengui $\mathrm{Li}^{2}$, Wenzheng Zhao ${ }^{1}$, Gefen Yin ${ }^{2}$, Jianping Liu ${ }^{2,4^{\star}}$, Shaoyu $\mathrm{He}^{1^{\star}}$ \\ ${ }^{1}$ Eastern Bee Research Institute, Yunnan Agricultural University, Kunming 650201, China \\ ${ }^{2}$ College of Animal Science and Technology, Yunnan Agricultural University, Kunming 650201, China \\ ${ }^{3}$ Chuxiong Prefecture Animal Disease Control Center, Chuxiong 675000, Yunnan Province, China \\ ${ }^{4}$ Karolinska Institute, Department of Biosciences and Nutrition, SE-14183 Huddinge, Sweden
}

"Corresponding author: Jianping Liu, Karolinska Institute, Department of Biosciences and Nutrition, SE-14183 Huddinge, Sweden, Tel: 858586658; E-mail: jianping.liu@ki.se

Shaoyu He, Eastern Bee Research Institute, Yunnan Agricultural University, Kunming 650201, China, Email: he_shaoyu@126.com

Rec date: Dec 17, 2015; Acc date: Jan 11, 2016; Pub date: Jan 13, 2016

Copyright: ( 2016 Wang M, et al. This is an open-access article distributed under the terms of the Creative Commons Attribution License, which permits unrestricted use, distribution, and reproduction in any medium, provided the original author and source are credited.

\begin{abstract}
Deformed wing virus (DWV), black queen cell virus (BQCV), sacbrood virus (SBV), Kashmir bee virus (KBV), acute bee paralysis virus (ABPV) and chronic bee paralysis virus (CBPV) are the most common RNA viruses in bee population worldwide. To determine the prevalence of these viruses in Apis cerana in Yunnan Province, China, 270 adult Eastern worker bee (A. cerana) samples have been collected from nine major bee breeding regions in Yunnan province for screening. Our data showed that BQCV, DWV, KBV and SBV are widely prevalent in Yunnan Province. The total prevalence rates of KBV, DWV, SBV and BQCV in Yunnan province were 3\%, 14.8\%, 24.1\% and 36.3\%, respectively. BQCV was detected in all selected regions except Jinghong City. The prevalence of KBV in Tengchong County is the first evidence, to our knowledge, showing that Eastern bees could be infected by KBV. The highest infection rate of SBV was found in Kunming city (56.7\%). Sequence analysis demonstrated high nucleotide homology between the isolated BQCV, DWV, KBV and SBV strains. Phylogenetic analysis showed that except SBV (YN07), Yunnan isolates can be likely clustered into independent branches, which indicates the possibility of geographic origins.
\end{abstract}

Keywords: Black queen cell virus; Deformed wing virus; Kashmir bee virus; Sacbrood virus; Apis cerana; Prevalence; Yunnan

\section{Introduction}

The Eastern bee (Apis cerana) has unique biological and behavioral characteristics, playing unique and important roles during the pollination of plants [1]. Located in the far southwest in China, bordering Myanmar, Laos, and Vietnam, Yunnan is the most biologically and culturally diverse province. This province contains snow-capped mountains and true tropical environment, thus supporting an unusually full spectrum of species and vegetation types. Among the multitudinous plant species, 148 are honey plants, and 75 of them are used for producing commercial honey [2]. As a result, bee products from Yunnan province rank as the third largest production in China.

Bee colonies have been continually declining worldwide over the past 50 years, the reasons for which have often been linked to the spread of the parasitic mite Varroa destructor and its interaction with certain bee viruses [3]. Both the European bees and the Asian bees are susceptible to a variety of viruses and some other pathogens. At least 18 viruses have been globally identified in different stages and castes of bees including eggs, larvae, pupae, adult workers, drones, and queens [4]. Six of these, i.e., deformed wing virus (DWV), black queen cell virus (BQCV), sacbrood virus (SBV), Kashmir bee virus (KBV), acute bee paralysis virus (ABPV) and chronic bee paralysis virus (CBPV), are the most common ribonucleic acid (RNA) viruses [5,6]. Like most insect-infecting RNA viruses, bee viruses usually persist in unapparent, asymptomatic infections, capable of replicating rapidly under certain conditions, which results in observable symptoms often leading to colony losses. Infection or co-infection with these viruses has been reported in the United States, Britain, France, Italy, Denmark, Japan and Thailand [5].

In the beginning of the 20th century, due to the lack of strict quarantine regulations, foulbrood in bees from Europe was transmitted to China which accompanied the introduction of the Western bee (Apis mellifera). Eastern bees were consequently infected and spread across China, causing huge losses to the bee keeping industry. In recent years, more and more Western bees have been introduced. The rising contact frequency between Western and Eastern bees has deteriorated the risk of the transmission of bee diseases. However, the prevalence state of the six most common RNA viruses in Eastern bees from Yunnan province is still unknown. In this study, we aim to investigate the prevalence of these six viruses in Eastern bees from nine major bee breeding regions of Yunnan province in China.

\section{Material and Methods}

\section{Sample collection}

Available beekeepers within the nine main beekeeping regions (Kunming City, Luoping County of Qujing prefecture, Mengzi City and Hekou County of Honghe autonomy prefecture, Jinghong City of Xishuangbanna autonomy prefecture, Wuding County and Dayao 
Citation: Wang M, Bi J, Wang L, Zhou D, Ma X, et al. (2016) Prevalence of Four Common Bee RNA Viruses in Eastern Bee Populations in Yunnan Province, China. J Veterinar Sci Technol 7: 284. doi:10.4172/2157-7579.1000284

Page 2 of 9

County of Chuxiong autonomy prefecture, Tengchong County of Baoshan prefecture, and Deqing County of Diqing autonomy prefecture) in Yunnan province were selected for sampling, according to the previously described method [7]. From each region, thirty single adult worker bees without displaying any observable pathological symptoms were randomly collected from a single colony in the hive in March 2010. All the two hundred and seventy bee samples were preserved in individual microcentrifuge tubes (one bee in one tube) in liquid nitrogen, brought back to the laboratory and stored in $-80^{\circ} \mathrm{C}$ for further analysis.

\section{Primers}

Based on sequence alignment, primers for DWV, SBV, CBPV, and ABPV were designed using Primier 5.0 (Premier Biosoft International, $\mathrm{CA}$, USA). Primers for BQCV and KBV were selected from the literature [8]. All primers were synthesized by Sangon Biotech Co, Ltd (Shanghai, China) and listed in Table 1.

\begin{tabular}{|c|c|c|c|c|c|}
\hline Primer & Primer Sequence (5'-3') & Position & $\begin{array}{l}\text { Reference } \\
\text { sequence }\end{array}$ & $\begin{array}{l}\text { Size of the } \\
\text { amplicon (bp) }\end{array}$ & Corresponding gene \\
\hline DWV-F & TCCATCAGGTTCTCCRATAAC & $9256-9276$ & \multirow{2}{*}{ AJ489744 } & \multirow{2}{*}{327} & \multirow{2}{*}{ polyprotein } \\
\hline DWV-R & GCCACAGGTCTAGTTGGATG & $9563-9582$ & & & \\
\hline SBV-F & TCGGATCCACCAAGTTGGAGG & 291-311 & \multirow{2}{*}{ AF092924 } & \multirow{2}{*}{349} & \multirow{2}{*}{ polyprotein } \\
\hline SBV-R & АССTCATCACTCTGGGTCCTT & 619-639 & & & \\
\hline BQCV-F & TGGTCAGCTCCCACTACCTTAAAC & $7850-7873$ & \multirow{2}{*}{ AF183905 } & \multirow{2}{*}{700} & \multirow{2}{*}{ Structural polyprotein } \\
\hline BQCV-R & GCAACAAGAAGAAACGTAAACCAC & $8527-8550$ & & & \\
\hline KBV-F & GATGAACGTCGACCTATTGA & $5406-5424$ & \multirow{2}{*}{ AY275710 } & \multirow{2}{*}{415} & \multirow{2}{*}{$\mathrm{RdRp}$} \\
\hline KBV-R & TGTGGGTTGGCTATGAGTCA & $5801-5819$ & & & \\
\hline ABPV-F & TTATGTGTCCAGAGACTGTATCCA & $8460-8483$ & \multirow{2}{*}{ AF150629 } & \multirow{2}{*}{901} & \multirow{2}{*}{ polyprotein } \\
\hline ABPV-R & GCTCCTATTGCTCGGTTTTTCGGT & $9337-9360$ & & & \\
\hline CBPV-F & CTTGGATCCGATTTCGCTC & $55-73$ & \multirow{2}{*}{ AF375659 } & \multirow{2}{*}{384} & \multirow{2}{*}{ RdRp } \\
\hline CBPV-R & GAGGTTGTACTCGACCTGAT & $419-438$ & & & \\
\hline
\end{tabular}

Table 1: Primers used in this study. F: forward, R: reverse.

\section{RNA extraction}

Individual adult worker bee sample was minced in liquid nitrogen and homogenized in Trizol (Invitrogen, California, USA). The total RNA for each sample was extracted following the manufacturer's protocol and dissolved in diethyl pyrocarbonate-treated water in the presence of an RNase inhibitor (Invitrogen). The concentration of total RNA was determined by measuring the absorption at $260 \mathrm{~nm}$, and the purity of RNA was estimated by the absorbance ratio of $260 \mathrm{~nm} / 280$ $\mathrm{nm}$ using a spectrophotometer. The RNA samples were stored at $-80^{\circ} \mathrm{C}$ prior to molecular detection of viruses.

\section{RT-PCR detection}

Using a one-step PCR kit (Takara Biotechnology Co Ltd, Dalian, China), PCR amplification conditions were optimized and finalized. The $25 \mu \mathrm{l}$ reaction contains template $1 \mu \mathrm{l}, \mathrm{MgCl}_{2}(25 \mathrm{mM}) 5 \mu \mathrm{l}, 10 \times$ One Step RNA PCR Buffer $2.5 \mu \mathrm{l}$, dNTP mixture (each $10 \mathrm{mM}$ ) $2.5 \mu \mathrm{l}$, RNase Inhibitor (40 U/ $\mu \mathrm{l}) 0.5 \mu \mathrm{l}$, AMV RTase XL ( $5 \mathrm{U} / \mu \mathrm{l}) 0.5 \mu \mathrm{l}$, AMVOptimized Taq $(5 \mathrm{U} / \mu \mathrm{l})$ 0.5ul, RNase free $\mathrm{dH} 2 \mathrm{O} 10.5 \mu \mathrm{l}$, forward primer and reverse primer $1 \mu \mathrm{l}$ for each. The conditions are as follow: reverse transcription at $50^{\circ} \mathrm{C}$ for 30 minutes, denaturation at $94^{\circ} \mathrm{C}$ for 2 minutes, then 35 cycles of denaturation for 30 seconds at $94^{\circ} \mathrm{C}$, annealing for 30 seconds to corresponding optimal temperature $\left(55^{\circ} \mathrm{C}\right.$ for SBV, $54^{\circ} \mathrm{C}$ for $\mathrm{BQCV}, 53^{\circ} \mathrm{C}$ for $\mathrm{DWV}, \mathrm{KBV}$, and $\mathrm{ABPV}$, and $56^{\circ} \mathrm{C}$ for $\mathrm{CPBV}$ ) and 1 minute elongation at $72^{\circ} \mathrm{C}$.

\section{Sequencing and phylogenetic analysis}

The PCR amplification products were excised from the agarose gel and extracted using a PCR product purification kit (BioTeke Corporation, Beijing, China) and ligated into pMD18-T vectors (Takara Biotechnology Co Ltd). The plasmids were then used to transform Escherichia Coli DH5a cells (Takara Biotechnology Co Ltd). The plasmids were extracted and the inserts were sequenced by Sangon Biotech Co, Ltd. The nucleotide sequence similarities between isolated sequences for each virus were calculated using Lasergene sequence analysis tools MegAlign (DNASTAR Inc, Madison, USA). Phylogenetic and molecular evolutionary genetics analyses were conducted using the neighbor-joining method with MEGA 4 (Temple, AZ, USA) [9]. Numbers at nodes correspond to bootstrap percentages with values of greater than 50 percent being regarded as phylogenetic grouping. Forty-four related reference strains were used as references in the analysis (Table 2).

\section{Results}

\section{RT-PCR detection}

The prevalence of these six common bee RNA viruses in Eastern bee populations in Yunnan Province was summarized in Figure 1. For BQCV, we identified 20 positive samples in Kunming City (66.7\%), 24 
Citation: Wang M, Bi J, Wang L, Zhou D, Ma X, et al. (2016) Prevalence of Four Common Bee RNA Viruses in Eastern Bee Populations in Yunnan Province, China. J Veterinar Sci Technol 7: 284. doi:10.4172/2157-7579.1000284

Page 3 of 9

in Luoping County (80.0\%), 16 in Mengzi City (53.3\%), 15 in Wuding County (50.0\%), 12 in Dayao County (40.0\%), 2 in Tengchong County (6.7\%), 8 in Deqin County (26.7\%) and 1 in Hekou County $(3.3 \%)$, with the total prevalence rate $36.3 \%(98 / 270)$. For DWV, 17, 12, 3, 2, and 2 positive bee samples were found in Kunming city $(76.7 \%)$, Luoping County (40.0\%), Wuding County (10.0\%), Deqin County (6.7\%) and Dayao County (6.7\%), respectively. The overall prevalence rate of DWV was $14.8 \%$ (40/270). For KBV, 8 of 30 samples $(26.7 \%)$ collected in Tengchong County were positive, with the other eight regions negative, and the overall total rate in Yunnan province was $3.0 \%$ (8/270). For SBV, 17 positive samples in Kunming City (56.7\%), 9 in Luoping County (30.0\%), 7 in Mengzi City (23.3\%), 12 in Jinghong city (40.0\%), 9 in Wuding County $(30.0 \%)$ and 11 in Dayao County (36.7\%) were detected, with a total prevalence rate of $24.1 \%(65 / 270)$. Primers for $\mathrm{ABPV}$ and $\mathrm{CBPV}$ did not reveal any positive samples in this study.

\begin{tabular}{|c|c|c|c|c|c|}
\hline Viruses & Strain name & Accession No. & Isolation source & Country & $\begin{array}{l}\text { Isolation/ } \\
\text { submitted date }\end{array}$ \\
\hline \multirow{10}{*}{ DWV } & unknown & AJ489744 & Apis mellifera & Italy & June 2002 \\
\hline & unknown & AY224602 & Apis mellifera & France & Jan 2003 \\
\hline & PA & AY292384 & Apis mellifera & USA & May 2003 \\
\hline & AUSTRIA-1 & DQ224278 & Apis mellifera & Austria & Jan 2007 \\
\hline & Warwick-2009 & GU109335 & Apis mellifera & UK & Oct 2009 \\
\hline & VDV-1-DWV-No-5 & HM067437 & Apis mellifera & UK & May 2009 \\
\hline & VDV-1-DWV-No-9 & HM067438 & Apis mellifera & UK & May 2009 \\
\hline & Warwick & HM162356 & Apis mellifera & UK & May 2009 \\
\hline & Zriffin & JF440526 & Zriffin Apiary & Israel & Oct 2008 \\
\hline & Chilensis A1 & JQ413340 & Apis mellifera & Chile & Oct 2011 \\
\hline \multirow{14}{*}{ SBV } & Austria & AF284617 & Apis mellifera & Austria & July 2000 \\
\hline & Germany 1 & AF284618 & Apis mellifera & Austria & July 2000 \\
\hline & Rothamstead & AF092924 & Apis mellifera & UK & Sep 1998 \\
\hline & Riez2002 & AY152711 & Apis mellifera & France & Sep 2002 \\
\hline & Sophia1 R80 & AY152712 & Apis mellifera & France & Sep 2002 \\
\hline & AFSSA P12 2002 & AY230517 & Apis mellifera & France & Feb 2003 \\
\hline & CSBV-LN & HM237361 & Apis cerana & China & Jan 2009 \\
\hline & Korea & HQ322114 & Apis cerana & South Korea & Aug 2010 \\
\hline & AmSBV-Kor21 & JQ390591 & Apis mellifera & South Korea & 2011 \\
\hline & CQ1 & JQ796779 & Apis cerana & China & March 2012 \\
\hline & Pennsylvania & AY626247 & Apis mellifera & USA & May 2004 \\
\hline & T73/05A & EF570887 & Apis mellifera & Denmark & Apr 2007 \\
\hline & South African & AF183905 & Apis mellifera & South African & Sep 1999 \\
\hline & Pennsylvania & AY626246 & Apis mellifera & USA & May 2004 \\
\hline \multirow{6}{*}{ BQCV } & 1 & DQ364629 & Apis mellifera & Uruguay & Jan 2006 \\
\hline & POLAND-4 & EF517519 & Apis mellifera & Poland & Mar 2007 \\
\hline & D6 & EU292211 & Apis mellifera & Brazil & Nov 2007 \\
\hline & CJ3 & EU375537 & unknown & South Korea & Nov 2007 \\
\hline & B1 & FJ603458 & unknown & South Korea & Dec 2008 \\
\hline & R4LY 51 & GU903461 & Apis mellifera & UK & Feb 2010 \\
\hline
\end{tabular}


Citation: Wang M, Bi J, Wang L, Zhou D, Ma X, et al. (2016) Prevalence of Four Common Bee RNA Viruses in Eastern Bee Populations in Yunnan Province, China. J Veterinar Sci Technol 7: 284. doi:10.4172/2157-7579.1000284

Page 4 of 9

\begin{tabular}{|c|c|c|c|c|c|}
\hline & 20W1-PA-USA-2006 & HQ655459 & Apis mellifera & USA & Nov 2006 \\
\hline & Kor1-BQCV2 & JN542438 & Apis cerana & South Korea & Aug 2011 \\
\hline & YY1 & JX149518 & Apis mellifera & South Korea & Jun 2012 \\
\hline \multirow{11}{*}{ KBV } & Canadian & AF034542 & Apis mellifera & USA & Nov 1999 \\
\hline & unknown & AF035359 & Apis mellifera & USA & Nov 2000 \\
\hline & unknown & AF052567 & Varroa jacobsoni & USA & Nov 2001 \\
\hline & 941227B-1 & AF085478 & Varroa jacobsoni & USA & Nov 1999 \\
\hline & $\mathrm{mfb} 6$ & AF135861 & Apis mellifera & USA & Mar 1999 \\
\hline & 990806B-13 & AF197906 & unknown & Russia & Nov 1999 \\
\hline & BALL-BRL9apv & AF233366 & Apis mellifera & USA & Feb 2000 \\
\hline & unknown & AY787143 & Apis mellifera & Germany & Oct 2004 \\
\hline & Varroa & AY821562 & unknown & Spain & Nov 2004 \\
\hline & JAK3 & FJ225118 & Apis cerana & Jordan & 2007 \\
\hline & KBV_3_TW & GU108224 & Apis cerana & China (Taiwan) & 2008 \\
\hline
\end{tabular}

Table 2: Reference sequences used in the phylogenetic analysis.

\section{Sequence and phylogenetic analysis}

After alignment, the viruses sharing the same sequences were considered as the same strains. In total, $12 \mathrm{BQCV}, 8 \mathrm{DWV}, 8 \mathrm{KBV}$, and $8 \mathrm{SBV}$ strains were identified from the two hundred and seventy bee samples, with the sequences confirmed by BLAST (http:// blast.ncbi.nlm.nih.gov/Blast.cgi) and submitted to GenBank, with the accession numbers and geographic origins listed in Table 3.

\begin{tabular}{|c|c|c|c|}
\hline Viruses & Nomination & Accession No. & Origin \\
\hline \multirow{8}{*}{ KBV } & kbv-YN01 & JX232598 & Tengchong County \\
\hline & kbv-YN02 & JX232599 & Tengchong County \\
\hline & kbv-YN03 & JX232600 & Tengchong County \\
\hline & kbv-YN04 & JX232601 & Tengchong County \\
\hline & kbv-YN05 & JX232602 & Tengchong County \\
\hline & kbv-YN06 & JX232603 & Tengchong County \\
\hline & kbv-YN07 & JX232604 & Tengchong County \\
\hline & kbv-YN08 & JX232605 & Tengchong County \\
\hline \multirow{7}{*}{ DWV } & dwv-YN01 & JX679473 & Kunming City \\
\hline & dwv-YN02 & JX679474 & Kunming City \\
\hline & dwv-YN03 & JX679475 & Kunming City \\
\hline & dwv-YN04 & JX679476 & Luoping County \\
\hline & dwv-YN05 & JX679477 & Luoping County \\
\hline & dwv-YN06 & JX679478 & Wuding County \\
\hline & dwv-YN07 & JX679479 & Dayao County \\
\hline
\end{tabular}

\begin{tabular}{|c|c|c|c|}
\hline & dwv-YN08 & JX679480 & Deqing County \\
\hline \multirow{8}{*}{ SBV } & sbv-YN01 & JX679481 & Kunming City \\
\hline & sbv-YN02 & JX679482 & Kunming City \\
\hline & sbv-YN03 & JX679483 & Dayao County \\
\hline & sbv-YN04 & JX679484 & Mengzi City \\
\hline & sbv-YN05 & JX679485 & Jinghong City \\
\hline & sbv-YN06 & JX679486 & Luoping County \\
\hline & sbv-YN07 & JX679487 & Luoping County \\
\hline & sbv-YN08 & JX679488 & Wuding County \\
\hline \multirow{12}{*}{$B Q C V$} & bqcv-YN01 & JN185928 & Luoping County \\
\hline & bqcv-YN02 & JN185929 & Luoping County \\
\hline & bqcv-YN03 & JN185930 & Luoping County \\
\hline & bqcv-YN04 & JN185931 & Kunming City \\
\hline & bqcv-YN05 & JN185926 & Wuding County \\
\hline & KM1 & JN185927 & Kunming City \\
\hline & bqcv-YN06 & JN185932 & Dayao County \\
\hline & bqcv-YN07 & JN379018 & Deqin County \\
\hline & bqcv-YN08 & JX679489 & Kunming City \\
\hline & bqcv-YN09 & JX679490 & Kunming City \\
\hline & bqcv-YN10 & JX679491 & Mengzi City \\
\hline & bqcv-YN11 & JX679492 & Tengchong County \\
\hline
\end{tabular}


Citation: Wang M, Bi J, Wang L, Zhou D, Ma X, et al. (2016) Prevalence of Four Common Bee RNA Viruses in Eastern Bee Populations in Yunnan Province, China. J Veterinar Sci Technol 7: 284. doi:10.4172/2157-7579.1000284

Page 5 of 9

\begin{tabular}{|l|l|l}
\hline bqcv-YN12 & JX679493 & Hekou County
\end{tabular}

Table 3: KBV, DWV, SBV and BQCV strains detected in Eastern bees from Yunnan Province.

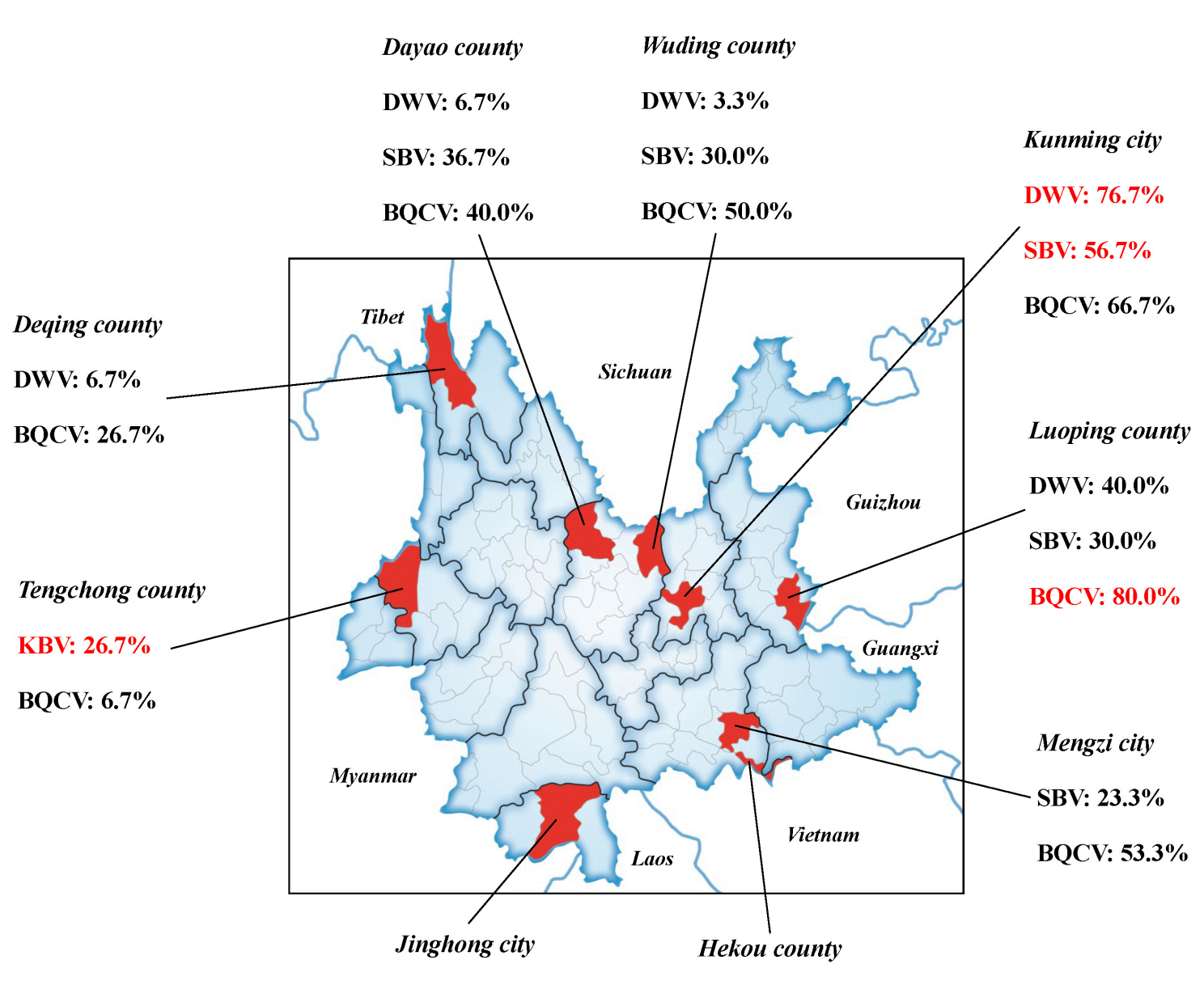

SBV: $40 \%$

BQCV: 3.3\%

Figure 1: Prevalence of DWV, SBV, KBV and BQCV in Eastern bee colonies in Yunnan Province.

Phylogenetic trees were constructed and bootstrap analysis was performed (Figure 2). Overview, all the virus isolates of BQCV, DWV, KBV and SBV from Yunnan province were grouped into independent cluster, respectively, except SBV YN07 fell into the reference sequence group. The BQCV samples in this study came from $A$. cerana in Yunnan province while the BQCV reference strains came from $A$. mellifera in Korea, USA, South Africa and Brazil. The nucleotide acid sequences of the isolated BQCV were $98.1 \%-100 \%$ identical between the 12 Yunnan isolates, and $94.3-99.6 \%$ to the 11 selected reference strains. Eight Chinese BQCV sequences in this study were aligned and compared to the sequences of the reference strains. The phylogenetic tree revealed that the eight BQCV isolated strains separated into three sub-groups: JH1 strain (JN379018) isolated in Xishuangbanna was more closely related to two references strains (EU375535, EU639830) that are known to be originally present in $A$. mellifera but were far from other isolates, while the Kunming isolated strains were located on an independent branch. Our results revealed that the virus has widely spread in $A$. cerana with prevalence rates as high as $80 \%$. The nucleotide acid sequences of the amplified products of the DWV isolated strains were 95.4\%-99.7\% identical between the eight Yunnan isolates, and $92.7 \%-96.6 \%$ to the 10 reference sequences selected from GenBank. Further sequence analysis revealed that the eight isolated KBV strains shared $99.0 \%-100 \%$ nucleotide homology between the Yunnan isolates and 76.1\%-95.4\% nucleotide homologies with the 11 selected reported strains. The nucleotide acid sequences of the amplified fragments of the eight isolated SBV strains share $94.3 \%-$ $100 \%$ nucleotide homology between the isolates and $94.0 \%-98.7 \%$ with the 12 selected references strains. 
Citation: Wang M, Bi J, Wang L, Zhou D, Ma X, et al. (2016) Prevalence of Four Common Bee RNA Viruses in Eastern Bee Populations in
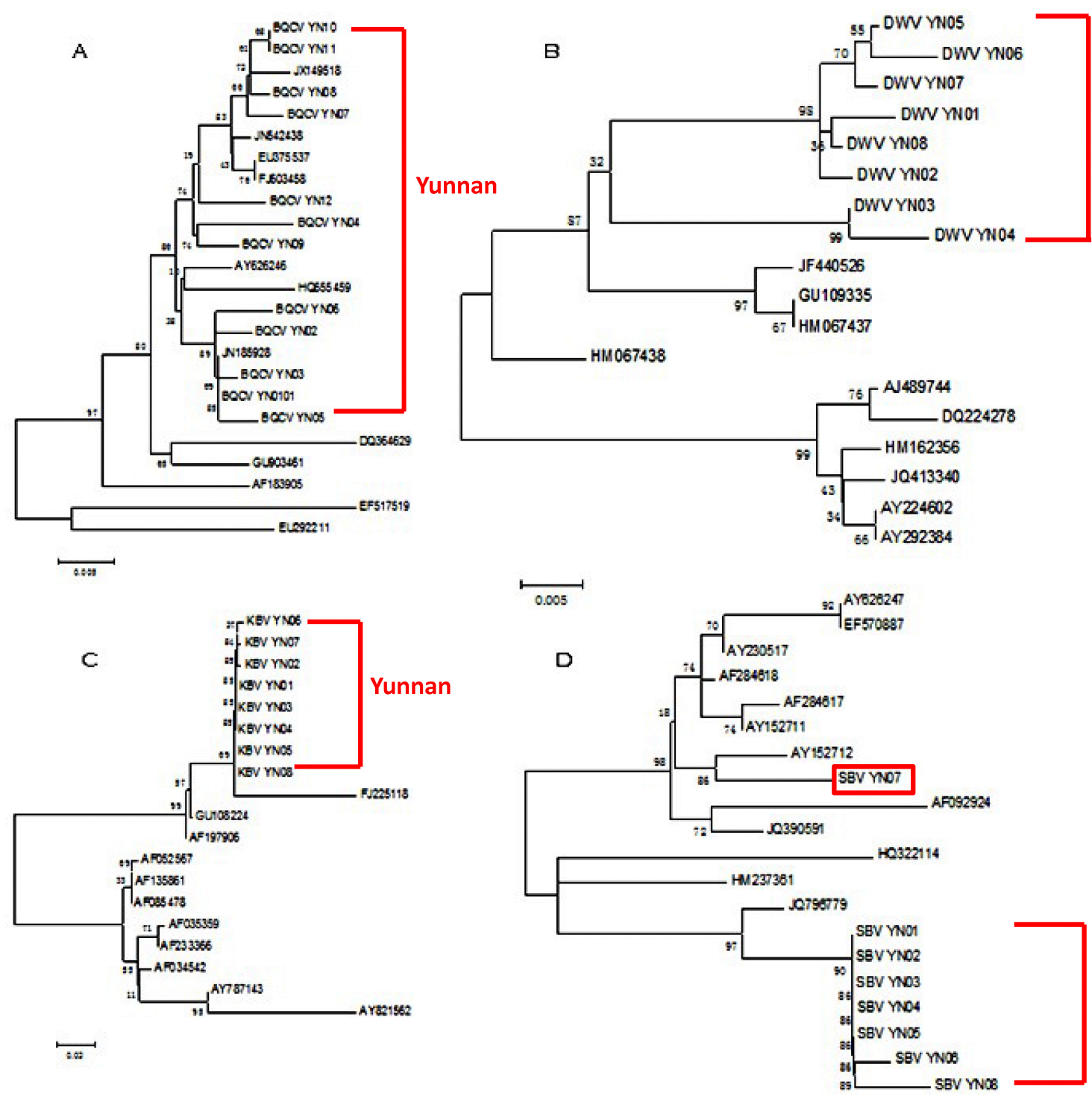

Yunnan

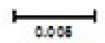

Figure 2: Phylogenetic tree constructed by aligning the BQCV, DWV, KBV and SBV detected in Yunnan Province.

\section{Determination of co-infection}

The present study found multiple virus infections in $20.0 \%(54 / 270)$ of the bee samples. Among the samples with multiple infections, the dual-infection (SBV/DWV, BQCV/SBV, BQCV/DWV or BQCV/KBV) rate was $83.3 \%(45 / 54)$ and the triple-infection (BQCV/SBV/DWV) rate was $16.7 \%(9 / 54)$. Co-infection with SBV and BQCV occurred at the highest frequency $(35.2 \%$; 19/54). The most common regions for co-infection were Kunming City and Luoping County (Table 4).

\begin{tabular}{|c|c|c|c|c|c|c|c|}
\hline \multirow[t]{2}{*}{ Co-infection type } & \multicolumn{7}{|c|}{ Sampling site } \\
\hline & Kunming & Luoping & Mengzi & Wuding & Dayao & Tengchong & Total \\
\hline SBV/DWV & 5 & 1 & 0 & 0 & 0 & 0 & 6 \\
\hline BQCV/SBV & 6 & 4 & 2 & 4 & 3 & 0 & 19 \\
\hline BQCV/DWV & 10 & 5 & 0 & 0 & 1 & 0 & 16 \\
\hline
\end{tabular}




\begin{tabular}{|l|l|l|l|l|l|l|l|}
\hline BQCV/KBV & 0 & 0 & 0 & 0 & 0 & 4 & 4 \\
\hline BQCV/SBV/DWV & 4 & 4 & 0 & 1 & 0 & 0 & 9 \\
\hline Total & 25 & 14 & 2 & 5 & 4 & 4 & 54 \\
\hline
\end{tabular}

Table 4: Frequency of dual and triple co-infections. The numbers shows the combinations of multiple virus infections, co-infection was found in 6 of 9 study regions.

\section{Discussion}

Before the introduction of superior varieties of Western bees into China, Eastern bees were the only breeding species. Eastern bees have unique biological and behavioral characteristics and play important roles as unique plant pollinators for commercially valuable crops, including oil crops, vegetables, and fruit trees, and as a wild nectar source [2]. Eastern bees are widely distributed in Yunnan province, from the low and hot valley of Hekou County (altitude $76.4 \mathrm{~m}$, south of Yunnan) to the high and cold region of Zhongdian County (altitude $3600 \mathrm{~m}$, northwest of Yunnan). Eastern bees can survive both in cold winter and in hot summer, providing various bee products (for example, honey and wax) with economic importance.

Bees in most parts of the world have undergone marked declines since the 1940s, one of the reason for this is that bees can be infected by at least 18 viruses and other pathogens [10]. Viral infection can occur during various growth and developmental stages of bees, but only a few of them result in serious disease. In earlier days, laboratory diagnosis of bee viruses was established based on electronic microscopic identification of the virus particles and antigens, and using techniques such as immunodiffusion test, radioimmunoassay, and enzyme-linked immunosorbent assay (ELISA) [11]. The sensitivity and specificity of most of these tests is low or they suffer from nonspecific amplification and it is difficult to distinguish different virus types using these traditional methods. The lack of cell culture and in vitro techniques further hampered the development of molecular diagnostic methods. This study established RT-PCR methods for the rapid detection of six of the most common bee RNA viruses with high sensitivity and analytic specificity, and identified the prevalence status of DWV, SBV, KBV and BQCV in Eastern Bee colonies in Yunnan province. Among the nine regions in which BQCV, SBV, and DWV were screened, Luoping County showed very high infection rates. This is of particular concern as thousands hectares of canola are planted in this area each year and, while canola plants are in bloom, large numbers of hives arrive to this relatively small geographical location from many different regions of the country. In addition, it is well known that bee breeding enhances virus transmission.

A survey of the prevalence of seven bee viruses in Western and Eastern bees in 18 provinces in China found that infection rates varied dramatically between the two bee species. DWV, BQCV, SBV, Israel acute paralysis virus (IAPV), ABPV and CBPV were prevalent in Western bees, with DWV being the most prevalent at 94\%. IAPV, DWV, CBPV, BQCV and SBV were found in Eastern bees, with SBV being the most dominant and present in $86 \%$ of apiaries [7].

SBV primarily affects bee broods, with color change in infected larvae from pearly white to pale yellow, and shortly after death they dry out, forming a dark brown gondola-shaped scale [12]. In China, SBV was first described in Guangdong province in 1972, and reemerged in Liaoning province in 2008, which caused lethal diseases in individual bees and the collapse of entire colonies [13]. A novel strain of SBV in Chinese bees that shares $86.8 \%$ nucleotide sequence homology and $93.4 \%$ amino-acid identity with reference strains has been detected in Guangdong Province [14]. SBV infection has also been reported prevalent in our neighboring countries like Thailand [15]. The present study revealed the presence of SBV (24.1\%) of the screened samples in Yunnan province, of which the highest infection rate was in Kunming (56.7\%). Considering that SBV mainly infects larvae, further studies focusing on the prevalence of this virus in larvae are needed to acquire specific prevalence data.

DWV infection is the most common in bees which has established persistent infection in most apiaries in the world since the first isolation of DWV in the early 1980s. DWV Infection is found in different bee castes including queens, drones, and workers, as well as in different bee developmental stages including eggs, larvae, pupae and adults. This virus is transmitted both vertically and horizontally [16]. While DWV usually persists as an asymptomatic infection, the virus can be re-activated when triggered by various host stress, causing symptoms of illness in infected bees [17]. The manifestations of the disease caused by DWV infection include shrunken and crumpled wings, decreased body size, discoloration in adult bees and a reduction in life span. The severe symptoms of DWV infections appear to be associated with Varroa destructor infestation of the bee hive, and studies have shown that Varroa destructor harbors even greater levels of the virus than found in severely infected bees [18]. A recent study [19] on 1140 A. cerana worker samples was performed in 19 provinces in China between November 2010 and January 2011. However, no data about DWV from Yunnan province was available in this study and only very limited spots were sampled. Our study revealed that $14.8 \%$ of screen samples were positive for DWV, the highest of which was present in Kunming (76.7\%), and this virus was also prevalent in Luoping County, Wuding County, Dayao County and Deqing County.

KBV was first confirmed in A. cerana Fabricius and analysis of the genome sequence shows that KBV is a cricket paralysis-like virus (Dicistroviridae cripavirus) [20,21]. Like most bee viruses, KBV is thought to persist as an asymptomatic infection within the bee community, until stress or an alternative vector (such as Varroa) activates it to become epidemic and lethal [22]. There is a report indicating that when KBV carrier bees are pierced and suckled by Varroa destructor, KBV is activated which results in viremia, thus causing a large number of bee deaths. However, as of yet, no one has found a way to culture bee viruses in vitro, which has hampered the study of viral diseases in bees. As a result, the relationship between crawling disease and Varroa destructor infection and the prevalence of $\mathrm{KBV}$ in China has yet to be fully elucidated. We found the positive rate of KBV in Yunnan province is $26.7 \%$, which is the first report of KBV infection in Eastern bees in China.

BQCV infection was more prevalent in adult bees than in pupae, but the infected worker bees normally do not exhibit significant disease symptoms and that the incidence of BQCV was higher in spring and 
summer than in autumn [23]. BQCV is the most common cause of death of queen larvae in Australia and Poland [21]. More and more BQCV strains have been isolated and identified from A. mellifera, making it the second most prevalent virus infection in this species after DWV [24]. The variability of BQCV isolates collected from a variety of geographic regions can be further understood by molecular comparison and determination of genomic relationships between the strains.

DWV is present in all developmental stages and castes, with significant economic importance due to its close association with bee colony collapse induced by Varroa destructor. DWV is considered as a common global bee virus which is present in both laboratory-reared and wild populations of bumble bees (Bombus huntii) [1,25] DWV and BQCV are common multi-host and prevalent viruses in European bees. Queen, worker or drone broods can be infected by these two viruses without apparent morphologic alterations, although symptomatic BQCV infection of such broods has also been reported [26].

Multiple infections with different viruses are very common in both Western and Eastern bees [27]. This phenomenon has also been reported in many countries including France, Hungary, USA, Austria, Southwest England and South Korea [7]. The dynamics of these coexisting virus populations within these colonies is of great interest and it would be useful to determine how they fluctuate with respect to each other [28]. Therefore, the incidence of dual and triple infections confirmed in this study is unsurprising.

$\mathrm{ABPV}$ and CBPV were not detected in this study, which is coincident with a previous investigation in Japan [29], where the study of Apis mellifera and Apis cerana japonica colonies with RT-PCR has revealed CBPV infection in $A$. mellifera but not in A. c. japonica colonies in Japan. The possible reasons why we did not detect ABPV or CBPV from Yunnan could be as follows: 1). The Apis cerana populations in the areas under investigation in Yunnan province are free of infection of ABPV and CBPV; 2). The virus titer was so low, which is beyond the detection sensitivity of classical RT-PCR: 3 ). After propagation and adaption in the Apis cerana, ABPV and CBPV accumulated sequence variation within the primer regions where we started the amplifications.

Although Eastern honey bee population in China is often infected with Varroa, the samples we collected were free of Varroa infestation. However, Varroa infestation was observed in the beehives where we collected the samples, which could be one of the reasons of virus transmission. Since these viruses are often latent in honey bees and our study was based mainly on qualitative detection of the viruses, it is unclear, to what extent the results are relevant for pathology, which is worth of further investigation. Furthermore, due to the unavailability of cell culture models for honey bee viruses, quantitative analysis of the titers of the viruses is technically and practically difficult. Recently, new viruses were discovered in Apis mellifera like Lake Sinai Virus [30], it can also be worthy to investigate these viruses in $A$. cerana in the future study.

In conclusion, our study investigated the prevalence of the six most common bee RNA viruses that are known to cause diseases in bee colonies in Yunnan Province of China. We demonstrated that BQCV, DWV, KBV and SBV are already widely prevalent in Yunnan province and that Luoping County and Kunming city had the highest infection rates. For the first time we showed that KBV could infect $A$. cerana and is already prevalent in Tengchong County. Phylogenetic analysis revealed that most of the Yunnan isolates are likely clustered into independent branches. We demonstrated a geographic separation of Yunnan isolates from most of the reference isolates. The lack of major exchange of honey bees between Europe/mainland US and Yunnan for the recent decades may have resulted in the geographic separation of Yunnan isolates. Therefore, the results in our study strongly suggest that sequence analysis can play an important role in tracing the origins of honey bee virus strains and diagnosis of honey bee disease in Chinese populations during epizootics.

\section{Acknowledgments}

This work was supported by a grant from the Modern Agroindustry Technology Research System of China (No. CARS-45-kxj14) and the Key Laboratory of Veterinary Public Health of Higher Education of Yunnan Province.

\section{Conflict of Interest}

The authors declare that they have no conflict of interest.

\section{References}

1. Xu P, Shi M, Chen XX (2009) Antimicrobial peptide evolution in the Asiatic honey bee Apis cerana. PLoS One 4: e4239.

2. He Shaoyu, Lin Zuncheng (2004) Eastern bee industry in Yunnan Province. Journal of Bee pp. 27-28.

3. Highfield AC, El Nagar A, Mackinder LC, Noël LM, Hall MJ, et al. (2009) Deformed wing virus implicated in overwintering honeybee colony losses. Appl Environ Microbiol 75: 7212-7220.

4. Genersch E (2010) Honey bee pathology: current threats to honey bees and beekeeping. Appl Microbiol Biotechnol 87: 87-97.

5. Chen YP, Siede R (2007) Honey bee viruses. Adv Virus Res 70: 33-80.

6. Singh R, Levitt AL, Rajotte EG, Holmes EC, Ostiguy N, Vanengelsdorp D, et al. (2010) RNA viruses in hymenopteran pollinators: evidence of interTaxa virus transmission via pollen and potential impact on non-Apis hymenopteran species. PLoS One 5: e14357.

7. Chen Y, Zhao Y, Hammond J, Hsu HT, Evans J, et al. (2004) Multiple virus infections in the honey bee and genome divergence of honey bee viruses. J Invertebr Pathol 87: 84-93.

8. Benjeddou M, Leat N, Allsopp M, Davison S (2001) Detection of acute bee paralysis virus and black queen cell virus from honeybees by reverse transcriptase pcr. Appl Environ Microbiol 67: 2384-2387.

9. Tamura K, Dudley J, Nei M, Kumar S (2007) MEGA4: Molecular Evolutionary Genetics Analysis (MEGA) software version 4.0. Mol Biol Evol 24: 1596-1599.

10. Forsgren E, de Miranda JR, Isaksson M, Wei S, Fries I (2009) Deformed wing virus associated with Tropilaelaps mercedesae infesting European honey bees (Apis mellifera). Exp Appl Acarol 47: 87-97.

11. Hung ACF, Shimanuki H, (1999) A scientific note on the detection of Kashmir bee virus in individual honeybees and Varroa jacobsoni mites. Apidologie 30: 353-354.

12. Yang JL, Yang R, Shen KF, Peng XW, XIong T, et al. (2012) Rapid detection of sacbrood virus (SBV) by one-step reverse transcription loopmediated isothermal amplification assay. Virol J 9: 47.

13. Mingxiao M, Ming L, Jian C, Song Y, Shude W, et al. (2011) Molecular and Biological Characterization of Chinese Sacbrood Virus LN Isolate. Comp Funct Genomics 2011: 409386.

14. Feng Jianxun, Yu Jianxiu, Jingqiang Z (1999) Cloning of Partial Structure Protein Gene from Chinese Sacbrood Virus. Acta Scientiarum Naturalium Universitatis Sunyatseni 38: 124-126.

15. Sanpa S, Chantawannakul P (2009) Survey of six bee viruses using RTPCR in Northern Thailand. J Invertebr Pathol 100: 116-119. 
Citation: Wang M, Bi J, Wang L, Zhou D, Ma X, et al. (2016) Prevalence of Four Common Bee RNA Viruses in Eastern Bee Populations in Yunnan Province, China. J Veterinar Sci Technol 7: 284. doi:10.4172/2157-7579.1000284

Page 9 of 9

16. Möckel N, Gisder S, Genersch E (2011) Horizontal transmission of deformed wing virus: pathological consequences in adult bees (Apis mellifera) depend on the transmission route. J Gen Virol 92: 370-377.

17. Williams GR, Rogers RE, Kalkstein AL, Taylor BA, Shutler D, et al. (2009) Deformed wing virus in western honey bees (Apis mellifera) from Atlantic Canada and the first description of an overtly-infected emerging queen. J Invertebr Pathol 101: 77-79.

18. Bowen-Walker PL, Martin SJ, Gunn A (1999) The transmission of deformed wing virus between honeybees (Apis mellifera L.) by the ectoparasitic mite varroa jacobsoni Oud J Invertebr Pathol 73: 101-106.

19. Li J, Qin H, Wu J, Sadd BM, Wang X, et al. (2012) The prevalence of parasites and pathogens in Asian honeybees Apis cerana in China. PLoS One 7: e47955.

20. Bailey L, Woods RD (1977) Two More Small RNA Viruses from Honey Bees and Further Observations on Sacbrood and Acute Bee-Paralysis Viruses. J Gen Virol 37: 175-182.

21. De Miranda JR, Drebot M, Tyler S, Shen M, Cameron CE, et al. (2004) Complete nucleotide sequence of Kashmir bee virus and comparison with acute bee paralysis virus. J Gen Virol 85: 2263-2270.

22. Lisa Ward, Ruth Waite, Neil Boonham, Tom Fisher, Kelly Pescod, et al. (2007) First detection of Kashmir bee virus in the UK using real-time PCR. Apidologie 38: 181-190.
23. Siede R, Büchler R (2003) Symptomatic Black Queen Cell Virus infection of drone brood in Hessian apiaries. Berl Munch Tierarztl Wochenschr 116: 130-133.

24. Allen M, Ball B, (1996) The incidence and world distribution of honey bee viruses. Bee World 77: 141-162.

25. De Miranda JR, Genersch E (2010) Deformed wing virus. J Invertebr Pathol 103 Suppl 1: S48-61.

26. Tapaszti Z, Forgách P, Kovágó C, Topolska G, Nowotny N, et al. (2009) Genetic analysis and phylogenetic comparison of Black queen cell virus genotypes. Vet Microbiol 139: 227-234.

27. Ai H, Yan X, Han R (2012) Occurrence and prevalence of seven bee viruses in Apis mellifera and Apis cerana apiaries in China. J Invertebr Pathol 109: 160-164.

28. Choe SE, Nguyen LT, Noh JH, Koh HB, Jean YH, et al. (2012) Prevalence and distribution of six bee viruses in Korean Apis cerana populations. J Invertebr Pathol 109: 330-333.

29. Morimoto T, Kojima Y, Yoshiyama M, Kimura K, Yang B, et al. (2012) Molecular identification of chronic bee paralysis virus infection in Apis mellifera colonies in Japan. Viruses 4: 1093-1103.

30. Daughenbaugh KF, Martin M, Brutscher LM (2015) Honey Bee Infecting Lake Sinai Viruses. Viruses 7: 3285-3309. 